\title{
Characteristics of the Two Asian Bumblebee Species Bombus friseanus and Bombus breviceps (Hymenoptera: Apidae)
}

\author{
Cheng Liang ${ }^{1,2}$, Guiling Ding ${ }^{1, *} \mathbb{C}$, Jiaxing Huang ${ }^{1}{ }^{\mathbb{D}}$, Xuewen Zhang ${ }^{2}$, Chunhui Miao ${ }^{2}$ and \\ Jiandong An $1, *(1)$ \\ 1 Key Laboratory for Insect-Pollinator Biology of the Ministry of Agriculture and Rural Affairs, Institute of \\ Apicultural Research, Chinese Academy of Agricultural Sciences, Beijing 100093, China; \\ liang1087@163.com (C.L.); huangjiaxing@caas.cn (J.H.) \\ 2 Institute of Sericulture and Apiculture, Yunnan Academy of Agricultural Sciences, \\ Mengzi 661101, Yunnan, China; zxw216226@163.com (X.Z.); mchanchor@hotmail.com (C.M.) \\ * Correspondence: dingguiling@caas.cn (G.D.); anjiandong@caas.cn (J.A.)
}

Received: 30 January 2020; Accepted: 2 March 2020; Published: 3 March 2020

check for updates

\begin{abstract}
This study compared the food plants, life cycle, colony development, and mating behaviour of the two Asian bumblebee species Bombus friseanus and B. breviceps, which are very important pollinators for many wild flowers and crops in local ecosystems. Both species were shown to be highly polylectic. Differences were observed in their life cycles and colony development patterns. The colony foundation rate of the field-collected queens was high in both species, $95.5 \%$ in $B$. friseanus and $86.5 \%$ in B. breviceps. The intervals from colony initiation to colony sizes of 30,60 , and 80 workers and to the first male and gyne emergence were significantly shorter in B. friseanus than in B. breviceps $(p<0.01)$. The development period of the first batch of workers showed no significant difference between the two species $(p>0.05)$. Compared with $B$. friseanus, B. breviceps produced remarkably higher numbers of workers (135 \pm 30 workers/colony in B. friseanus and $318 \pm 123$ workers/colony in B. breviceps) and males (199 \pm 46 males/colony in B. friseanus and $355 \pm 166$ males/colony in B. breviceps) $(p<0.01)$, with notable variation was found among the colonies in both species. With no significant difference in the mating rate between these two species, the copulation duration of $B$. breviceps $(1.54 \pm 0.63 \mathrm{~min})$ was strikingly shorter than that of $B$. friseanus $(27.44 \pm 11.16 \mathrm{~min})(p<0.001)$. This study highlights the characteristics of the two Asian bumblebee species and will aid further studies on their conservation and agricultural pollination use.
\end{abstract}

Keywords: Bombus friseanus; Bombus breviceps; food plants; life history; colony development; mating

\section{Introduction}

Bumblebees are distributed mainly in the world's north-temperate regions [1]. Most bumblebees are annual social insects. Only mated queens survive the winter, hibernating in small cavities. In early spring, they leave their hibernation sites to found new colonies. First, the queen produces a batch of diploid eggs that will develop into the first batch of workers to initiate the colony. These workers assist the queen in raising subsequent broods that first develop into more workers and then into sexual individuals (males and gynes). Then, the mated new queens go into diapause while the mother queen, the males, and the workers die [2].

Bumblebees are important pollinators of many wild plants and crops, so they provide vital pollination services in both natural and agricultural ecosystems $[3,4]$. The exploitation of the potential of bumblebees for crop pollination should be based on the propagation of natural populations and the domestication. Domestication attempts involve controlling every step of the bumblebee's life cycle. 
Commercial rearing started only if the bumblebees had been domesticated [3]. Currently, the main species reared commercially is the B. terrestris from Eurasia. To date, the commercial B. terrestris has been deliberately introduced into many foreign territories for crop pollination because of its recognized value $[3,5]$.

However, the intentional introduction of this alien species has led to biological invasion in many countries [6-9]. The accidental escapees and intention spread of non-native bumblebees may affect native plant reproduction [10], and these introduced bees may compete for food resources and nesting sites with native species $[7,11]$, spread new diseases and parasites [12,13], and disrupt the reproduction of native bumblebee species [14,15].

Considering that $B$. terrestris would strongly impact the indigenous ecosystems, attempts to rear native bumblebee species have been conducted in many countries, such as $B$. impatiens and B. occidentalis in North America [16], B. ignitus in South Korea [17,18], B. hypocrita and B. ignitus in Japan [19-21], and B. ignitus, B. lucorum, B. pyrosoma, B. picipes, B. lantschouensis, and B. patagiatus in China $[22,23]$. Most reared species belong to the subgenus Bombus s. str., with few species from the subgenera Pyrobombus and Melanobombus.

B. friseanus and B. breviceps, belonging to the subgenera Melanobombus and Alpigenobombus, respectively, are distributed mainly in the regions of Southern China, Himalaya, and Southeast Asia [24]. They are also the two most abundant bumblebee species in Yunnan Province of Southwest China [25]. These two Asian bumblebee species are important pollinators for many plants and play key roles in local ecosystems. For instance, B. friseanus is an important pollinator for alpine plants, such as Pedicularis species [26-28] and Salvia przewalskii (Lamiaceae) [29,30]. B. breviceps is the major pollinator of Amomum subulatum [31,32]. In this study, to evaluate whether B. friseanus and B. breviceps have the potential for domestication and commercial applications, we first surveyed their food plants across Yunnan Province and then monitored their life history in Mengzi city, Yunnan Province. The colony development and the mating behaviour of these two species were also recorded and compared under rearing room conditions.

\section{Materials and Methods}

\subsection{Investigating Food Plants}

From 2002 to 2017, a systematic survey of bumblebees was ongoing in China [1,22]. The survey of bumblebees in Yunnan Province was conducted extensively between 2009 and 2017. Information on the food plants visited by B. friseanus and B. breviceps was compiled from all the records collected during the survey.

\subsection{Monitoring the Life History}

The life cycles of both B. friseanus and B. breviceps were observed in Mengzi city, Yunnan Province, between 2016 and 2017. Observations were carried out three times a month, on the 5th, 15th, and 25th, respectively. When it was rainy, the field work was postponed until the next sunny day. For each field observation, we recorded the presence of queens, workers, and males for both species for $1 \mathrm{~h}$.

\subsection{Bumblebees Laboratory Rearing}

During mid-March and early April 2016 and 2017, B. breviceps queens and B. friseanus queens that had emerged from diapause were collected in the field from Mengzi city, Yunnan Province. Each queen was reared individually in a small "starting box" (wooden box sized $16 \times 12 \times 16 \mathrm{~cm}$ ) kept in an identical dark climate room at $29 \pm 1{ }^{\circ} \mathrm{C}$ and $57 \% \pm 2 \%$ relative humidity for nest initiation. The small colony was transferred into a larger "rearing box" (wooden box sized $31 \times 24 \times 16 \mathrm{~cm}$ ) when the first batch of workers (usually 4-6 workers) emerged.

During the rearing experiment, the bumblebees were fed ad libitum with sugar syrup (50\% sugar content, w/w) and commercially available fresh pollen collected by the honey bee Apis mellifera. 


\subsection{Recording the Colony Development}

The colony development of B. breviceps and B. friseanus was tracked by direct daily observation under red light. The developmental traits were recorded, including data on the queen's first oviposition (colony initiation); the developmental time for the first batch of workers; the times when colonies reached 30, 60, and 80 workers; and the date of the first male and gyne emergence. As soon as the first male or gyne emerged, they were removed from the colony and reared in separate boxes. At the end of the colony's life, we counted all the workers, males, and gynes produced by each colony. During the observation, we also counted the dead bees in the colonies to determine the total number of workers and sexual individuals produced. The colony lifetime was defined as the date when the colony had approximately 30 workers left after the old queen had died.

\subsection{Observing the Mating Behaviour}

Copulation of both B. breviceps and B. friseanus was observed in rectangular fine netting cages $(2.0 \times 1.2 \times 1.5 \mathrm{~m})$. The newly emerged queens and males were collected from laboratory-reared colonies and transferred to separate boxes for rearing. For each observation, ten queens at eight days after emergence were released into the mating cages a few minutes after three times as many males (10-15 days old) had been put in. The queens and males present in a mating cage were collected from different colonies to avoid inbreeding. The queens were discarded if they had not mated within $1 \mathrm{~h}$ (for B. breviceps) or $2 \mathrm{~h}$ (B. friseanus) after being placed in the mating cage. To investigate the mating duration (the length of time that copulation takes), we recorded the time for 30 mating pairs for both bumblebee species. After completion of the first copulation, we marked mated B. breviceps queens and B. friseanus queens and put them back in the mating cage to observe if a second mating occurred.

\section{Results}

\subsection{The Food Plants of B. friseanus and B. breviceps}

We recorded a total of 85 plant species belonging to 26 families that were foraged by $B$. friseanus and B. breviceps in Yunnan Province. Our survey noted that B. friseanus foraged the flowers of 49 plant species across 17 families. There were 47 plant species belonging to 17 different plant families visited by B. breviceps (Table S1). The most common plants foraged by B. friseanus included Trifolium repens, Clinopodium megalanthum, and Cirsium lidjiangense, belonging to the families Fabaceae, Lamiaceae, and Asteraceae, respectively. B. breviceps was found to forage on Crotalaria assamica (Fabaceae) and Rubus alceaefolius (Rosaceae) in many places. The major foraging resources of both species were plants of the families Fabaceae and Lamiaceae (Figures 1 and 2). Foraging of $B$. friseanus workers on plentiful species of Scrophulariaceae and Asteraceae was also observed. There were 11 plant species foraged by both B. friseanus and B. breviceps (Table S1). 


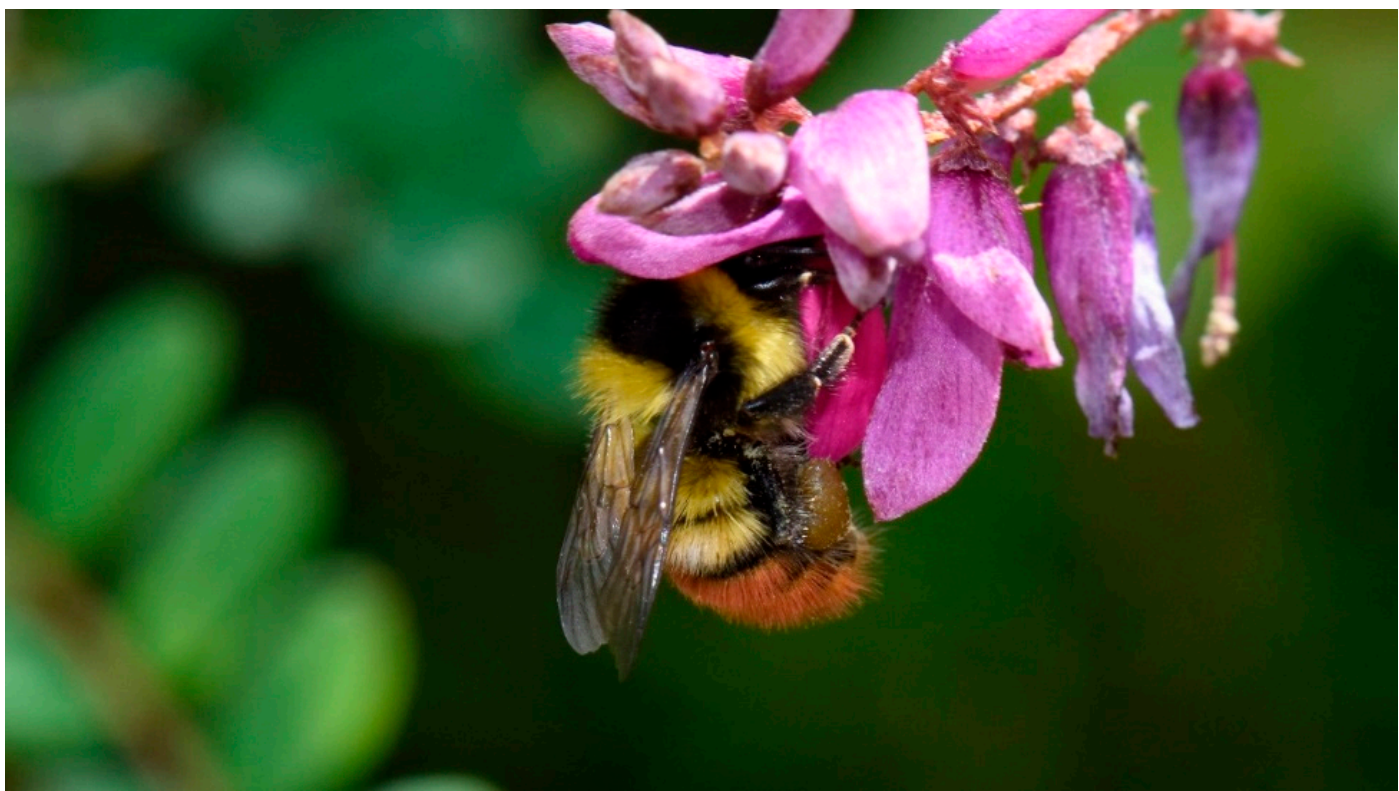

Figure 1. Bombus friseanus worker visiting Indigofera forrestii (Fabaceae) in Yunnan Province of Southwest China (Photo by Jiaxing Huang).

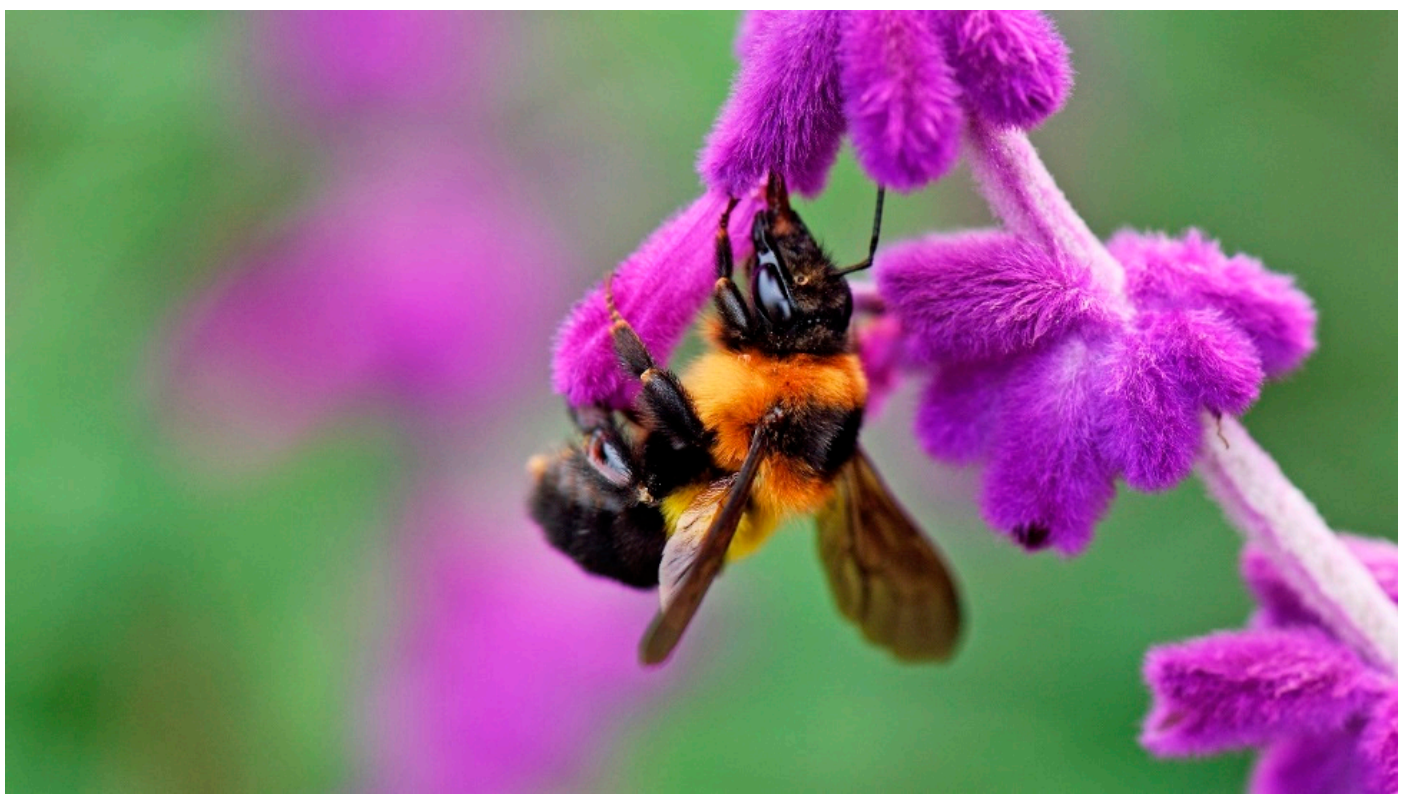

Figure 2. Bombus breviceps worker visiting Salvia leucantha (Lamiaceae) in Yunnan Province of Southwest China (Photo by Jiaxing Huang).

\subsection{The Life History of B. friseanus and B. breviceps}

Comparing the life cycles of the two species, the flying season of $B$. breviceps lasted longer than $B$. friseanus, although the queens of $B$. friseanus emerged from hibernation earlier, and so did the first workers and sexual reproductions. For $B$. friseanus, the hibernated queens started nest searching in early March. Workers were observed to forage during early April until mid-September. The males and gynes appeared during July and September. For B. breviceps, the overwintered queens started to found new colonies in late March, and the workers began to forage in early May, which could last until mid-December. The reproductive males were observed during the early September until mid-December and the gynes appeared during the late September until late November (Figure 3). 


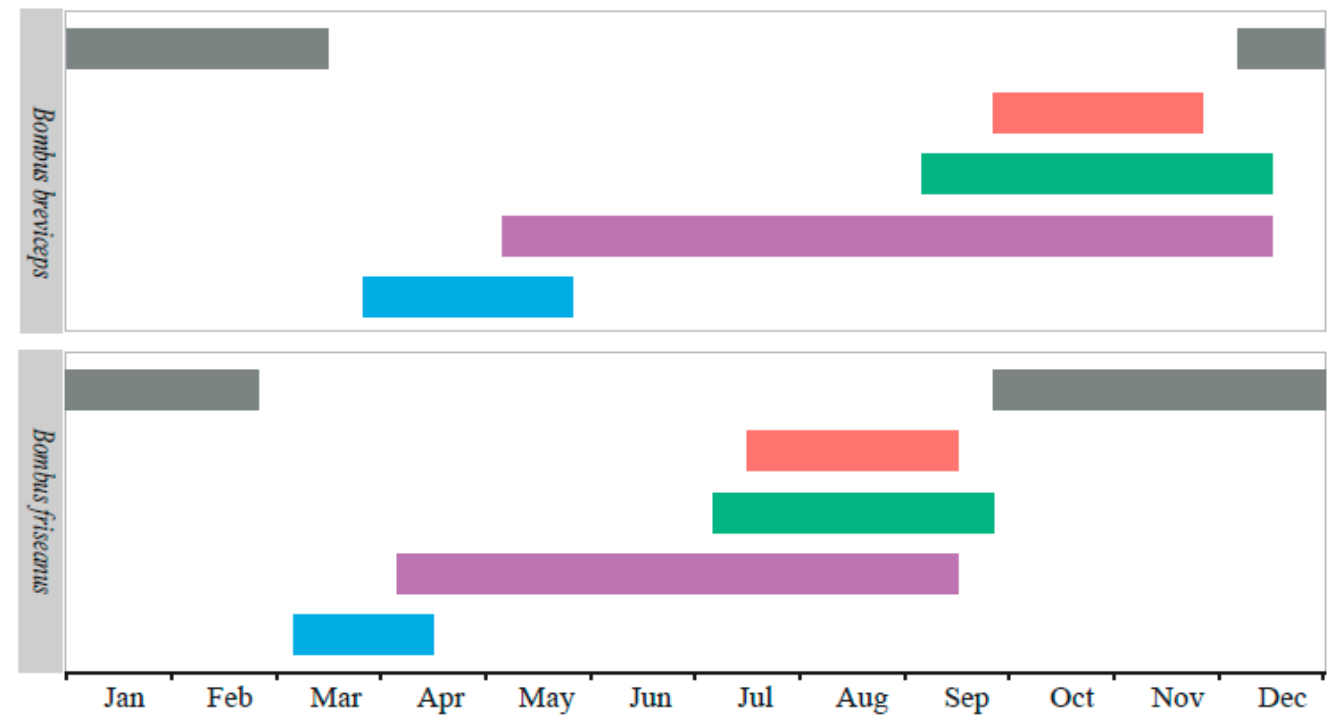

Figure 3. The life history of Bombus friseanus and Bombus breviceps in the field in Mengzi city, Yunnan Province, China. Blue bars (-) indicate the seasonal occurrence of hibernated queens, purple bars $(\square)$ for workers, green bars $(\square)$ for males, red bars $(\square)$ for gynes, and gray bars $(\square)$ for mated queens in hibernation.

\subsection{The Colony Development of B. friseanus and B. breviceps}

A total of $22 \mathrm{~B}$. friseanus queens and $111 \mathrm{~B}$. breviceps queens were collected from the field during the spring in 2016 and 2017. During rearing in the climate room, most queens started to lay eggs and initiate colonies, with no significant difference in the nesting rate between the two species $(95.5 \%$ in B. friseanus and $86.5 \%$ in B. breviceps; $\chi^{2}=0.677, d f=1, p=0.411$ ). The duration until first oviposition (the preoviposition period since queens were collected from the field) was $8.9 \pm 7.7$ days in B. friseanus and $13.6 \pm 7.0$ days in B. breviceps (Mann-Whitney $U$ test: $p=0.052$ ). There was no significant difference in the period until first worker emergence between the two species (Mann-Whitney $U$ test: $p=0.456$ ). The intervals from colony initiation to colony sizes of 30,60, and 80 workers were significantly shorter in B. friseanus than in B. breviceps (Mann-Whitney $U$ test: $p<0.01$ ). The period up to the first male and gyne emergence was also significantly shorter $(p<0.01)$ in $B$. friseanus (males: $60.6 \pm 5.1$ days, gynes: $73.5 \pm 5.9$ days) than in B. breviceps (males: $120.4 \pm 12.7$ days, gynes: $141.2 \pm 16.0$ days). The colony lifetime of B. breviceps was significantly longer than that of B. friseanus $(217.8 \pm 21.7$ and $132.5 \pm 15.5$ days, respectively; $p<0.01$ ) (Table 1 ).

For the first batch of workers, no significant difference was detected in the average developmental duration (26.6 \pm 3.2 days in B. breviceps and $25.9 \pm 1.8$ days in B. friseanus; Mann-Whitney $U$ test: $p=0.595)$. The developmental time of the egg, larvae, and pupae of the first batch of workers also showed no significant difference between B. friseanus and B. breviceps $(p>0.05)$. Although the egg, larval, and pupal periods of $B$. friseanus ( $3.4 \pm 0.7$ days; $11.6 \pm 1.6$ and $10.9 \pm 0.7$ days, respectively) were slightly shorter than that of $B$. breviceps ( $3.6 \pm 1.0$ days; $11.7 \pm 2.6$ and $11.3 \pm 1.7$ days) (Figure 4 ). 
Table 1. Comparison of duration (days) up to different phases between B. friseanus and B. breviceps colonies initiated by field-collected queens reared in the laboratory.

\begin{tabular}{|c|c|c|c|c|c|c|c|c|c|}
\hline Bumblebee Species & $\begin{array}{l}\text { Number of } \\
\text { Colonies }\end{array}$ & $\begin{array}{c}\text { Initial } \\
\text { Oviposition }\end{array}$ & $\begin{array}{c}\text { First Worker } \\
\text { Emergence }\end{array}$ & $\begin{array}{l}\text { Colony Size } \\
\text { of } 30 \text { Workers }\end{array}$ & $\begin{array}{l}\text { Colony Size } \\
\text { of } 60 \text { Workers }\end{array}$ & $\begin{array}{l}\text { Colony Size } \\
\text { of } 80 \text { Workers }\end{array}$ & $\begin{array}{l}\text { First Male } \\
\text { Emergence }\end{array}$ & $\begin{array}{l}\text { First Gyne } \\
\text { Emergence }\end{array}$ & $\begin{array}{l}\text { Colony } \\
\text { Lifetime }\end{array}$ \\
\hline & 13 & $8.9 \pm 7.7 \mathrm{a}$ & $25.4 \pm 1.8 \mathrm{a}$ & $38.8 \pm 5.0 \mathrm{a}$ & $46.2 \pm 5.2 \mathrm{a}$ & $53.6 \pm 5.5 \mathrm{a}$ & $60.6 \pm 5.1 \mathrm{a}$ & $73.5 \pm 5.9 \mathrm{a}$ & $132.5 \pm 15.5 \mathrm{a}$ \\
\hline Bombus breviceps & 20 & $13.6 \pm 7.0 \mathrm{a}$ & $26.5 \pm 8.1 \mathrm{a}$ & $62.1 \pm 13.2 b$ & $76.2 \pm 15.0 \mathrm{~b}$ & $87.8 \pm 17.8 \mathrm{~b}$ & $120.4 \pm 12.7 \mathrm{~b}$ & $141.2 \pm 16.0 \mathrm{~b}$ & $217.8 \pm 21.7 \mathrm{~b}$ \\
\hline
\end{tabular}

Same letters in the same column indicate no difference at $p>0.05$ level and different letters indicate significant difference at $p<0.01$ according to the Mann-Whitney $U$ test. 


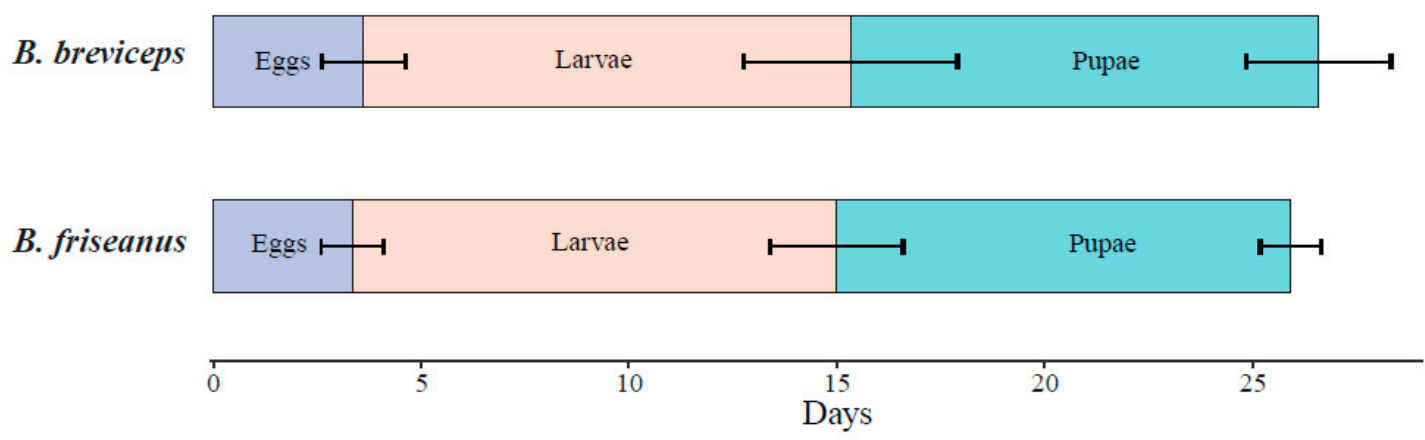

Figure 4. Developmental time (days) of the first batch of workers in Bombus friseanus $(\mathrm{N}=14)$ and Bombus breviceps $(\mathrm{N}=45)$. Horizontal bars indicate the standard deviation.

Even kept under the same laboratory conditions, colonies of B. friseanus and B. breviceps showed tremendous variation in the number of workers and males produced. In $B$. friseanus, the number of workers per colony ranged from 86 to 202, and the number of males ranged from 109 to 276. Larger variation was detected in B. breviceps colonies; 60-663 workers and 108-921 males could be produced per colony (Figure 5). Significant differences in the numbers of workers (135 \pm 30 workers/colony in B. friseanus and $318 \pm 123$ workers/colony in B. breviceps; $t=-8.108, d f=41.250, p<0.01$ ) and males (199 \pm 46 males/colony in B. friseanus and $355 \pm 166$ males/colony in B. breviceps; Mann-Whitney $U$ test: $p<0.01$ ) were observed between these two species. For the number of gynes, no significant differences were detected between the two species (63 \pm 21 gynes/colony in B. friseanus and $47 \pm 31$ gynes/colony in B. breviceps; Mann-Whitney $U$ test: $p=0.115$ ) (Figure 5). The field-collected queens of $B$. breviceps produced significantly stronger colonies (721 \pm 255 bees/colony) than did those of $B$. friseanus (397 \pm 91 bees/colony) $(t=-6.466, d f=45.484, p<0.01)$.

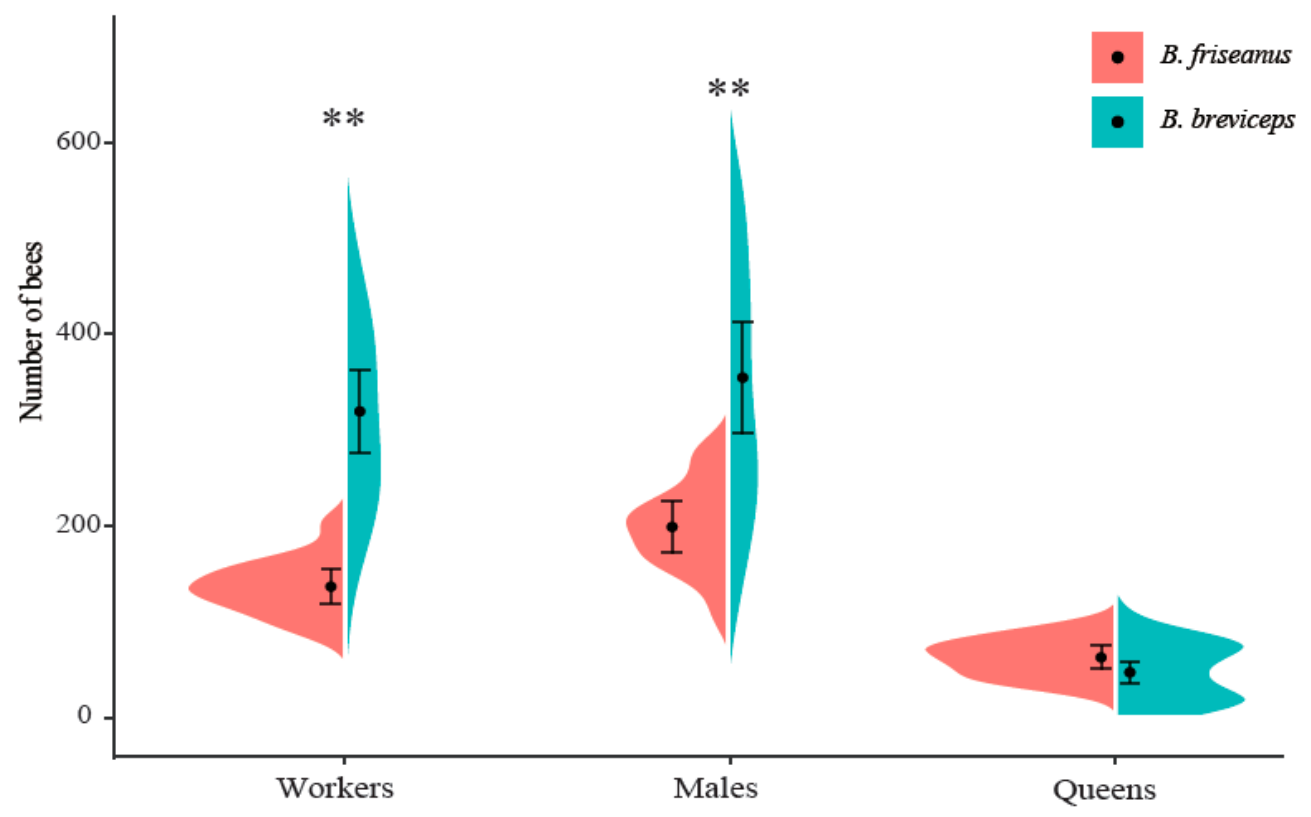

Figure 5. Colony size of Bombus friseanus $(\mathrm{N}=14)$ and Bombus breviceps $(\mathrm{N}=34)$ under laboratory rearing conditions. Black dots indicate the mean values and horizontal bars indicate the standard deviation. Asterisks represent level of significance. ${ }^{* *} p<0.01$.

\subsection{The Mating Behaviour of B. friseanus and B. breviceps}

There was no significant difference in the mating rate between these two species, with $62.96 \%$ in B. friseanus and $57.53 \%$ in B. breviceps $\left(\chi^{2}=1.449, d f=1, p=0.229\right)$. The copulation duration of B. friseanus $(27.44 \pm 11.16 \mathrm{~min})$ was significantly longer than that of $B$. breviceps $(1.54 \pm 0.63 \mathrm{~min})$ 
(Mann-Whitney $U$ test: $p<0.001$ ) (Table 2). Given the opportunity, re-mating occurred in none of the mated $B$. friseanus queens, while $10.07 \%$ of B. breviceps queens had a second mating (Table 2).

Table 2. Mating behaviour of B. friseanus and B. breviceps.

\begin{tabular}{ccccccc}
\hline & \multicolumn{2}{c}{ Mating Success } & \multicolumn{2}{c}{ Mating Duration } & \multicolumn{2}{c}{ Queens Re-mated } \\
\cline { 2 - 7 } Bumblebee Species & $\begin{array}{c}\text { Number of } \\
\text { Queens }\end{array}$ & $\begin{array}{c}\text { Mating Rate } \\
\mathbf{( \% )}\end{array}$ & $\begin{array}{c}\text { Number of } \\
\text { Mating } \\
\text { Pairs }\end{array}$ & $\begin{array}{c}\text { Mating Duration } \pm \text { S. } \\
\text { E. (min) }\end{array}$ & $\begin{array}{c}\text { Number of } \\
\text { Queens } \\
\text { Observed }\end{array}$ & $\begin{array}{c}\text { Queens } \\
\text { Re-mated } \\
(\%)\end{array}$ \\
\hline Bombus friseanus & 259 & $62.96 \mathrm{a}$ & 30 & $27.44 \pm 10.97 \mathrm{a}$ & 149 & 0 \\
Bombus breviceps & 216 & $57.53 \mathrm{a}$ & 30 & $1.54 \pm 0.62 \mathrm{~b}$ & 136 & 10.07
\end{tabular}

Same letters in the same column indicate no difference at $p>0.05$ level and different letters indicate significant difference at $p<0.01$.

\section{Discussion}

Both $B$. friseanus and B. breviceps were found to forage on plenty of plant species in Yunnan Province, indicating that they are polylectic. These two species were also reported to visit diverse plants in Sichuan Province [24]. B. friseanus and B. breviceps were distributed in different regions with different flora, reflecting their diverse floral host range for the collection of nectar and pollen. Further detailed studies focusing on the nutrition needs of these species would promote their domestication and commercial rearing system.

In many sites that we surveyed, both B. friseanus and B. breviceps were the most abundant species, co-existing with many other bumblebee species. Given the species richness at one location, competition or different foraging preferences between species may occur. Foraging bumblebees of one species could avoid flowers already visited by other species in a mixed community. This phenomenon has been reported by Goulson et al. (1998): Both B. terrestris and B. pascuorum could selectively avoid inflorescences of Symphytum officinale already visited by other Bombus species [33]. Notably, B. friseanus and $B$. breviceps share major foraging resources, and further research is necessary to elucidate the competitive foraging interactions between them.

Mating duration has been recorded in several bumblebee species. Similar or longer average copulation durations as those of $B$. friseanus have been reported: $42.2 \mathrm{~min}$ in B. bifarius, $44.7 \mathrm{~min}$ in $B$. californicus [34], 30.3-36.9 min in B. terrestris [35], $26.3 \mathrm{~min}$ in B. hypnorum [36], $28.9 \mathrm{~min}$ in B. ignitus, $27.3 \mathrm{~min}$ in B. patagiatus, and $20.6 \mathrm{~min}$ in B. lantschouensis [23]. Considerably shorter durations have been reported for B. frigidus (10.2 $\mathrm{min}$ ) and B. rufocinctus ( $9 \mathrm{~min}$ ) [34]. Our observed mating duration of B. breviceps $(1.5 \mathrm{~min}$ ) is extremely shorter than that of other species reported in previous studies. This is the shortest reported record for mating duration in all bumblebee species. Currently, little is known about the proximate reasons underlying mating duration variations.

So far, most Bombus species examined appear to be monandrous [23,37-39], with the exception that B. hypnorum and a few other species have been confirmed to be polyandrous [40,41]. The occurrence of second mating in B. breviceps queens suggests that this species may be another naturally polyandrous species. Without analysis of natural colonies, we are unable to draw solid conclusions based on such a low re-mating rate under laboratory conditions, especially considering that female choice to re-mate may depend upon the previous time spent mating [36]. Previous studies suggest that $B$. terrestris males impose monandry on queens by inserting a mating plug during copulation $[35,42,43]$; the fatty acids in mating plugs could prevent further mating of $B$. terrestris queens [42]. It was also suggested that the copulation of $B$. terrestris lasted $37 \mathrm{~min}$ to match the time required to deposit the ' $\mathrm{mating}$ plug' fully [35]. Hence, comparison of the mating plug between monandrous species and polyandrous species is needed to shed light on the proximate factors related to mating times and duration.

Nectar robbing refers to the collection of nectar by biting or piercing holes in flowers, often without providing an effective pollination service $[44,45]$. Flowering plants with long tubular flowers or nectar spurs are most likely to be robbed [46]. Previous studies reported that Salvia przewalskii was robbed by B. friseanus $[29,30]$. During our field collection, we also observed that Salvia leucantha was 
robbed by B. breviceps (Figure 2). Since nectar robbing can have diverse consequences on the host plants, ranging from detrimental to beneficial effects on plant reproductive success [47], pollination of plants with long corolla tubes should be performed with caution using B. friseanus and B. breviceps. Additionally, further studies are needed to reveal the effects of nectar robbing on pollinator behaviour and plant reproduction.

Previous studies have already revealed that Chinese B. lucorum, B. patagiatus, B. ignitus, B. pyrosoma, B. picipes, and B. lantschouensis are easy to rear and have promising application prospects $[22,23]$. The selected B. patagiatus and B. lantschouensis are being used in trials with fruit crops on local farms in north China and the pollination efficiencies of domestic bumblebees are comparable to that of imported $B$. terrestris. However, there are still some problems, such as low reproductive efficiency, high production cost, and unstable production process, need to be overcome [22]. For now, there is no commercial system developed for the mass production of native bumblebees in China.

Colony initiation with queens collected in the field is the first step for domestication attempts. Our study showed that the colony foundation rates of B. friseanus and B. breviceps field-collected queens were $95.5 \%$ and $86.5 \%$, respectively. This value resembles that reported in $B$. terrestris [48]. For pollination applications, it is desirable to have strong, long-lasting colonies. Worker productivity is an important criterion in evaluating the potential pollination efficiency of a bumblebee species. A minimum of 50 workers in $B$. terrestris colonies is necessary for providing normal pollination services [3,48]. Striking variations in colony size were detected among colonies in B. terrestris [2], B. lucorum [49], B. impatiens [50], B. friseanus, and B. breviceps (this study). Colonies of B. friseanus and $B$. breviceps could reach an average size of 135 and 318 workers, respectively. The mating success of the progeny queens was also high. These excellent biology traits displayed in different life cycles make these two species promising candidates for domestication and commercial rearing. To facilitate the domestication of $B$. friseanus and B. breviceps, further studies on year-round rearing and selective breeding are now in progress.

\section{Conclusions}

In conclusion, we studied the food plants, life cycle, colony development, and mating behaviour of Bombus friseanus and B. breviceps. Our results showed that these two Asian bumblebee species are highly polylectic. The colony foundation rate of the field-collected queens was high in both species. Although a notable difference was detected in the colony development pattern and mating behaviour between $B$. friseanus and B. breviceps, both species could produce colonies with remarkably high number of workers. Our results support that both B. friseanus and B. breviceps are promising candidates for domestication and commercial rearing. However, further studies on year-round rearing and selective breeding are needed for mass production of these two species' colonies.

Supplementary Materials: The following is available online at http://www.mdpi.com/2075-4450/11/3/163/s1, Table S1: Plant species visited by Bombus friseanus and Bombus breviceps.

Author Contributions: Conceptualization, C.L., G.D., and J.A.; methodology, C.L., X.Z., and C.M.; validation, all authors; formal analysis, C.L. and G.D.; investigation, C.L., X.Z., and C.M.; data curation, C.L., X.Z., and J.A.; writing—original draft preparation, C.L. and G.D.; writing—review and editing, C.L., G.D., J.H., and J.A.; visualization, G.D. and J.H.; supervision, X.Z. and J.A.; project administration, C.L. and J.D.; funding acquisition, C.L. and J.A. All authors have read and agreed to the published version of the manuscript.

Funding: This research was financially supported by the National Natural Science Foundation of China (31672500 and 31860685), the Key Laboratory project (2016FMZS06), and the Agricultural Science and Technology Innovation Program (CAAS-ASTIP-2015-IAR).

Acknowledgments: We are very thankful to Paul H. Williams for his help in identifying the bumblebees. We thank Zhiyong Zhou, Yazhou Zhao, Wenfeng Chen, Weiting Luo, Wenfei Song, Rui Su, Chuntao Zhou, and Runfa Ran for their help in collecting and rearing bumblebees and collecting food plants records. We also thank Dr. Lei Meng of China Agricultural University for her assistance in identifying the food plants.

Conflicts of Interest: The authors declare no conflict of interest. The funders had no role in the design of the study; in the collection, analyses, or interpretation of data; in the writing of the manuscript, or in the decision to publish the results. 


\section{References}

1. Williams, P.; Huang, J.; An, J. Bear wasps of the Middle Kingdom: A decade of discovering China's bumblebees. Antenna 2017, 41, 21-24.

2. Beekman, M.; Van Stratum, P. Does the diapause experience of bumblebee queens Bombus terrestris affect colony characteristics? Ecol. Entomol. 2000, 25, 1-6. [CrossRef]

3. Velthuis, H.H.W.; Van Doorn, A. A century of advances in bumblebee domestication and the economic and environmental aspects of its commercialization for pollination. Apidologie 2006, 37, 421-451. [CrossRef]

4. Goulson, D.; Lye, G.C.; Darvill, B. Decline and conservation of bumble bees. Annu. Rev. Entomol. 2008, 53, 191-208. [CrossRef]

5. Rasmont, P.; Coppee, A.; Michez, D.; De Meulemeester, T. An overview of the Bombus terrestris (L. 1758) subspecies (Hymenoptera: Apidae). Ann. Soc. Entomol. Fr. 2008, 44, 243-250. [CrossRef]

6. Hingston, A.B.; Marsden-Smedley, J.; Driscoll, D.A.; Corbett, S.; Fenton, J.; Anderson, R.; Plowman, C.; Mowling, F.; Jenkin, M.; Matsui, K.; et al. Extent of invasion of Tasmanian native vegetation by the exotic bumblebee Bombus terrestris (Apoidea: Apidae). Austral Ecol. 2002, 27, 162-172. [CrossRef]

7. Matsumura, C.; Yokoyama, J.; Washitani, I. Invasion status and potential ecological impacts of an invasive alien bumblebee, Bombus terrestris L. (Hymenoptera: Apidae) naturalized in Southern Hokkaido, Japan. Glob. Environ. Res. 2004, 8, 51-66.

8. Inoue, M.N.; Yokoyama, J.; Washitani, I. Displacement of Japanese native bumblebees by the recently introduced Bombus terrestris (L.) (Hymenoptera: Apidae). J. Insect Conserv. 2008, 12, 135-146. [CrossRef]

9. Tsuchida, K.; Kondo, N.I.; Inoue, M.N.; Goka, K. Reproductive disturbance risks to indigenous Japanese bumblebees from introduced Bombus terrestris. Appl. Entomol. Zool. 2010, 45, 49-58. [CrossRef]

10. Dohzono, I.; Kunitake, Y.K.; Yokoyama, J.; Goka, K. Alien bumble bee affects native plant reproduction through interactions with native bumble bees. Ecology 2008, 89, 3082-3092. [CrossRef]

11. Sáez, A.; Morales, C.L.; Garibaldi, L.A.; Aizen, M.A. Invasive bumble bees reduce nectar availability for honey bees by robbing raspberry flower buds. Basic Appl. Ecol. 2017, 19, 26-35. [CrossRef]

12. Jones, C.M.; Brown, M.J.F. Parasites and genetic diversity in an invasive bumblebee. J. Anim. Ecol. 2014, 83, 1428-1440. [CrossRef] [PubMed]

13. Schmid-Hempel, R.; Eckhardt, M.; Goulson, D.; Heinzmann, D.; Lange, C.; Plischuk, S.; Escudero, L.R.; Salathe, R.; Scriven, J.J.; Schmid-Hempel, P. The invasion of southern South America by imported bumblebees and associated parasites. J. Anim. Ecol. 2014, 83, 823-837. [CrossRef] [PubMed]

14. Kanbe, Y.; Okada, I.; Yoneda, M.; Goka, K.; Tsuchida, K. Interspecific mating of the introduced bumblebee Bombus terrestris and the native Japanese bumblebee Bombus hypocrita sapporoensis results in inviable hybrids. Naturwissenschaften 2008, 95, 1003-1008. [CrossRef] [PubMed]

15. Tsuchida, K.; Yamaguchi, A.; Kanbe, Y.; Goka, K. Reproductive interference in an introduced bumblebee: Polyandry may mitigate negative reproductive impact. Insects 2019, 10, 59. [CrossRef] [PubMed]

16. Macfarlane, R.P.; Patten, K.D.; Royce, L.A.; Wyatt, B.K.W.; Mayer, D.F. Management potential of sixteen North American bumble bee species. Melanderia 1994, 50, 1-12.

17. Mah, Y.I.; Lee, M.Y.; Bilinski, M. Some charateristics of korean indigenous bumblebee species (hymenoptera; Bombus spp.) under laboratory conditions. Acta Hortic. 2001, 561, 287-291. [CrossRef]

18. Yoon, H.J.; Kim, S.E.; Kim, Y.S. Temperature and humidity favorable for colony development of the indoor-reared bumblebee, Bombus ignitus. Appl. Entomol. Zool. 2002, 37, 419-423. [CrossRef]

19. Ono, M.; Mitsuhata, M.; Sasaki, M. Use of introduced Bombus terrestris worker helpers for rapid development of Japanese native B. hypocrita colonies (Hymenoptera, Apidae). Appl. Entomol. Zool. 1994, 29, 413-419. [CrossRef]

20. Hannan, M.D.; Maeta, Y.; Hoshikawa, K. Colony development of two species of Japanese bumble bees Bombus ignitus and Bombus hypocrita reared under artificial condition. Jpn. J. Entomol. 1997, 65, 343-354.

21. Asada, S.; Ono, M. Difference in colony development of two Japanese bumblebees, Bombus hypocrita and $B$. ignitus (Hymenoptera: Apidae). Appl. Entomol. Zool. 2000, 35, 597-603. [CrossRef]

22. Huang, J.; An, J. Species diversity, pollination application and strategy for conservation of the bumblebees of China. Biodivers. Sci. 2018, 26, 486-497. [CrossRef]

23. Zhang, H.; Zhou, Z.; Huang, J.; Yuan, X.; Ding, G.; An, J. Queen traits and colony size of four bumblebee species of China. Insects Soc. 2018, 65, 537-547. [CrossRef] 
24. Williams, P.; Tang, Y.; Yao, J.; Cameron, S. The bumblebees of Sichuan (Hymenoptera: Apidae, Bombini). Syst. Biodivers. 2009, 7, 101-189. [CrossRef]

25. Liang, C.; Zhang, X.; Huang, J.; Song, W.; Zhang, H.; Luo, W.; An, J. Biogeography and species diversity of bumblebees in Yunnan, Southwest China. Chin. J. Appl. Entomol. 2018, 55, 1045-1053. [CrossRef]

26. Tang, Y.; Xie, J.; Sun, H. Pollination ecology of Pedicularis muscoides H. L. Li subsp. himalayca Yamazaki from alpine areas of western Sichuan, China. Arct. Antarct. Alp. Res. 2007, 39, 481-487. [CrossRef]

27. Yu, W.; Li, D.; Wang, H. Highly efficient pollination by bumblebees ensures seed production in Pedicularis lachnoglossa (Orobanchaceae), an early-flowering Himalayan plant. J. Syst. Evol. 2012, 50, 218-226. [CrossRef]

28. Corbet, S.A.; Huang, S.Q. Buzz pollination in eight bumblebee-pollinated Pedicularis species: Does it involve vibration-induced triboelectric charging of pollen grains? Ann. Bot. 2014, 114, 1665-1674. [CrossRef]

29. Ye, Z.; Jin, X.; Wang, Q.; Yang, C.; Inouye, D.W. Nectar replenishment maintains the neutral effects of nectar robbing on female reproductive success of Salvia przewalskii (Lamiaceae), a plant pollinated and robbed by bumble bees. Ann. Bot. 2017, 119, 1053-1059. [CrossRef]

30. Ye, Z.; Jin, X.; Inouye, D.W.; Wang, Q.; Yang, C. Variation in composition of two bumble bee species across communities affects nectar robbing but maintains pollinator visitation rate to an alpine plant, Salvia przewalskii. Ecol. Entomol. 2018, 43, 363-370. [CrossRef]

31. Deka, T.N.; Sudharshan, M.R.; Saju, K.A. New record of bumble bee, Bombus breviceps Smith as a pollinator of large cardamom. Curr. Sci. 2011, 100, 926-928.

32. Deka, T.N.; Gudade, B.; Saju, K.A.; Vijayan, A.; Chhetri, P. Foraging behaviour of bumble bee (Bombus breviceps) in large cardamom (Amomum subulatum Roxb.) at Dzongu, North Sikkim. Ecol. Env. Cons. 2014, 20, 197-199.

33. Goulson, D.; Hawson, S.A.; Stout, J.C. Foraging bumblebees avoid flowers already visited by conspecifics or by other bumblebee species. Anim. Behav. 1998, 55, 199-206. [CrossRef] [PubMed]

34. Foster, R.L. Nestmate recognition as an inbreeding avoidance mechanism in bumble bees (Hymenoptera: Apidae). J. Kans. Entomol. Soc. 1992, 65, 238-243.

35. Duvoisin, N.; Baer, B.; Schmid-Hempel, P. Sperm transfer and male competition in a bumblebee. Anim. Behav. 1999, 58, 743-749. [CrossRef]

36. Brown, M.J.F.; Baer, B.; Schmid-Hempel, R.; Schmid-Hempel, P. Dynamics of multiple-mating in the bumble bee Bombus hypnorum. Insects Soc. 2002, 49, 315-319. [CrossRef]

37. Estoup, A.; Scholl, A.; Pouvreau, A.; Solignac, M. Monoandry and polyandry in bumble bees (Hymenoptera; Bombinae) as evidenced by highly variable microsatellites. Mol. Ecol. 1995, 4, 89-93. [CrossRef]

38. Schmid-Hempel, R.; Schmid-Hempel, P. Female mating frequencies in Bombus spp. from Central Europe. Insects Soc. 2000, 47, 36-41. [CrossRef]

39. Kokuvo, N.; Toquenaga, Y.; Goka, K. Effective paternity in natural colonies of Japanese native bumble bees. Ecol. Res. 2009, 24, 1111-1115. [CrossRef]

40. Paxton, R.J.; Thoren, P.A.; Estoup, A.; Tengö, J. Queen-worker conflict over male production and the sex ratio in a facultatively polyandrous bumblebee, Bombus hypnorum: The consequences of nest usurpation. Mol. Ecol. 2001, 10, 2489-2498. [CrossRef]

41. Payne, C.M.; Laverty, T.M.; Lachance, M.A. The frequency of multiple paternity in bumble bee (Bombus) colonies based on microsatellite DNA at the B10 locus. Insects Soc. 2003, 50, 375-378. [CrossRef]

42. Baer, B.; Morgan, E.D.; Schmid-Hempel, P. A nonspecific fatty acid within the bumblebee mating plug prevents females from remating. Proc. Natl. Acad. Sci. USA 2001, 98, 3926-3928. [CrossRef] [PubMed]

43. Sauter, A.; Brown, M.J.F. To copulate or not? The importance of female status and behavioural variation in predicting copulation in a bumblebee. Anim. Behav. 2001, 62, 221-226. [CrossRef]

44. Inouye, D.W. The effect of proboscis and corolla tube lengths on patterns and rates of flower visitation by bumblebees. Oecologia 1980, 45, 197-201. [CrossRef]

45. Irwin, R.E.; Bronstein, J.L.; Manson, J.S.; Richardson, L. Nectar robbing: Ecological and evolutionary perspectives. Annu. Rev. Ecol. Evol. Syst. 2010, 41, 271-292. [CrossRef]

46. Irwin, R.E.; Maloof, J.E. Variation in nectar robbing over time, space, and species. Oecologia 2002, 133, 525-533. [CrossRef]

47. Maloof, J.; Inouye, D. Are nectar robbers cheaters or mutualists? Ecology 2000, 81, 2651-2661. [CrossRef] 
48. Gösterit, A.; Gürel, F. Comparison of development patterns of imported and native Bombus terrestris L. (Hymenoptera: Apidae) colonies in the Mediterranean coastal region. Turk. J. Vet. Anim. Sci. 2005, 29, 393-398.

49. Müller, C.B.; Schmid-Hempel, P. Variation in life-history pattern in relation to worker mortality in the bumble-bee, Bombus lucorum. Funct. Ecol. 1992, 6, 48-56. [CrossRef]

50. Cnaani, J.; Schmid-Hempel, R.; Schmidt, J.O. Colony development, larval development and worker reproduction in Bombus impatiens Cresson. Insects Soc. 2002, 49, 164-170. [CrossRef]

(C) 2020 by the authors. Licensee MDPI, Basel, Switzerland. This article is an open access article distributed under the terms and conditions of the Creative Commons Attribution (CC BY) license (http://creativecommons.org/licenses/by/4.0/). 